\title{
Permeabilidade a quente de refratários para revestimento de cubas eletrolíticas
}

\section{(Hot permeability of refractories for aluminum electrolytic cells lining at high temperatures)}

\author{
D. Y. Miyaji ${ }^{1}$, F. A. O. Valenzuela ${ }^{1}$, M. A. L. Braulio ${ }^{1}$, P. Bonadia ${ }^{2}$, V. C. Pandolfelli ${ }^{1}$ \\ ${ }^{I}$ Grupo de Engenharia e Microestrutura de Materiais - GEMM \\ Departamento de Engenharia de Materiais, Universidade Federal de S. Carlos \\ Rod. Washington Luiz, km 235, C.P. 676, S. Carlos, SP, 13565-905 \\ ${ }^{2}$ Alcoa Alumínio S.A. \\ Rodovia Poços-Andradas km 10, Poços de Caldas, $M G$ \\ g207039@polvo.ufscar.br,vicpando@power.ufscar.br
}

\begin{abstract}
Resumo
Na indústria do alumínio primário, um dos principais responsáveis pela deterioração do revestimento refratário nas cubas de redução eletrolítica é o ataque por banho criolítico com alta concentração de $\mathrm{NaF}$, que penetra e reage com o refratário podendo, em condições extremas, causar a parada prematura de operação da cuba e grandes prejuízos econômicos. Baseando-se nos mais recentes estudos de caracterização de refratários para cubas, uma boa correlação tem sido encontrada entre a resistência à corrosão e a permeabilidade, a qual é calculada pela equação de Forchheimer para a obtenção das constantes $k_{1}$ Darciana (efeito viscoso) e k, não Darciana (efeito inercial). Entretanto, na maioria das situações, as medidas da permeabilidade têm sido efetuadas à temperatura ambiente, embora o refratário em uso esteja a superior temperatura. Este trabalho visa avaliar como esta permeabilidade se altera em temperaturas de até $700{ }^{\circ} \mathrm{C}$ buscando, assim, uma melhor correlação dos resultados com as condições reais de operação. Pretende-se também, investigar essa propriedade em refratários empregados no revestimento de cadinhos para o transporte de alumínio líquido, com o intuito de verificar a aplicabilidade da permeametria como uma ferramenta de caracterização desses materiais cujo interesse de aplicação e desenvolvimento tem sido cada vez maior.
\end{abstract}

Palavras-chave: refratário, alumínio, permeabilidade.

\begin{abstract}
In the aluminium primary industry, one of the main causes for electrolytic cells lining deterioration is the chemical attack by high NaF content cryolitic bath, that penetrates and reacts with the refractory, shortening the cell's service life and resulting great economic losses. Based on the most recent studies on characterization of alumino-silicate refractories for aluminum cell linings, a good correlation has been found between its chemical attack by molten fluorides and the permeability, which is calculated by Forchheimer's equation in order to obtain the Darcian constant $k_{1}$ (viscous effects) and non-Darcian constant $k_{2}$ (inertial effects). Nevertheless, in the majority of the situations permeability parameters are obtained at room temperature. This work aims to study how the increasing temperature affects permeability from room temperature up to $700{ }^{\circ} \mathrm{C}$ in these materials, in order to reproduce the operational conditions. It's also the objective to investigate the permeability of lining refractories for molten aluminum transport crucibles and evaluate the technological viability of such measurement technique for these materials.
\end{abstract}

Keywords: refractory, aluminium, permeability.

\section{INTRODUÇÃO}

Durante a operação, os materiais refratários usados na indústria do alumínio ficam expostos a agentes agressivos capazes de causar grandes danos ao revestimento, promovendo elevados custos de manutenção e parada prematura do equipamento. Como uma das formas de ataque é a penetração destes agentes através dos poros dos materiais, torna-se fundamental um melhor entendimento de sua microestrutura. Neste contexto, a medida de permeabilidade surge como uma ferramenta de caracterização que pode fornecer informações a respeito da capacidade do material em conter a infiltração. Sendo a agressividade do banho criolítico a principal responsável pela deterioração do revestimento refratário de cubas eletrolíticas, a medida da permeabilidade é imprescindível para a seleção de um material adequado. Adicionalmente, refratários cujo uso implica no contato direto com o alumínio líquido, como os utilizados em fornos e em cadinhos, também têm o seu tempo de vida útil relacionado à facilidade com que o metal fundido percola pelos poros e reage com o refratário. 
A permeabilidade de refratários para cubas tem sido medida usualmente a temperatura ambiente, ou seja, em situações muito distintas das condições reais de operação. Sendo assim, neste trabalho, foi avaliado qual o efeito da temperatura sobre a permeabilidade de uma nova geração de refratários comercias para cubas eletrolíticas e em um refratário que pode ser utilizado no revestimento de cadinhos de transporte de alumínio líquido. Embora a máxima temperatura de ensaio $\left(700^{\circ} \mathrm{C}\right)$ ainda esteja um pouco abaixo à de operação, os resultados poderão delinear as tendências dessa propriedade, verificando o potencial de aplicação tecnológica da permeametria a quente.

\section{Refratários para revestimento de catodos em cubas eletrolíticas}

De acordo com Siljan [1, 2], Walz [3] e Bonadia et al. [4], refratários sílico-aluminosos com baixa razão $\mathrm{Al}_{2} \mathrm{O}_{3} / \mathrm{SiO}_{2}$ apresentam maior resistência ao ataque por banho criolítico enriquecido por fluoreto de sódio. Isto ocorre devido à formação de fases com alta viscosidade, como a albita, na temperatura de contato entre o banho criolítico e o revestimento. Neste caso, a albita se torna uma barreira física para conter o banho, colaborando para uma menor velocidade de reação. Esses estudos têm também demonstrado que os refratários com maiores teores de alumina, apesar de sofrerem uma menor transformação mineralógica ao longo do período de operação, acabam por reduzir o tempo de vida da cuba, pois permitem que o banho criolítico penetre em seus poros até atingir o isolamento térmico, o que, por conseqüência, altera o balanço térmico da cuba.

Dessa forma, cinco refratários comerciais para revestimento de cubas foram selecionados para o presente estudo, sendo quatro destes materiais escolhidos por apresentarem adequada razão $\mathrm{Al}_{2} \mathrm{O}_{3} / \mathrm{SiO}_{2}(\sim 0,35)$. Além disso, optou-se pela análise de um refratário com maior teor de alumina $\left(\mathrm{Al}_{2} \mathrm{O}_{3} / \mathrm{SiO}_{2}=0,77\right)$, que embora seja quimicamente não adequado, tem sido usado no revestimento de cubas.

\section{Refratários para contato e transporte de alumínio líquido}

O mercado de refratários para a indústria do alumínio tem, cada vez mais, se especializado em produtos para os diferentes tipos de equipamentos. Isto se deve as mudanças nos processos de obtenção de novas ligas que submetem os revestimentos refratários a condições cada vez mais agressivas [5].

O transporte de alumínio fundido apresenta uma série de vantagens das quais se destacam:

- A entrega do metal fundido reduz a demanda energética do cliente, ou seja, não requer grandes investimentos para se efetuar a refusão do alumínio.

- O metal pode ser recebido com as especificações químicas desejadas, não havendo a necessidade de adição dos elementos de liga para a obtenção dos produtos.

- Dada a natureza do processo, o metal é entregue sob demanda, o que reduz estoques [6].

Considerando-se que a vida útil do revestimento está relacionada à sua corrosão, a adequada seleção dos refratários deve priorizar a procura por composições contendo óxidos termodinamicamente compatíveis e uma microestrutura pouco permeável.

Óxidos estáveis e agentes anti-molhantes colaboram para o controle químico da reação. Fisicamente, é possível reduzir a penetração do banho por meio do controle da distribuição do tamanho de poro, procurando minimizar seu diâmetro. Neste contexto, a permeabilidade pode ser uma importante ferramenta para uma avaliação do grau de conectividade dos poros. Braulio et al. [7] relatam que a questão microestrutural é fundamental em uma análise sistêmica para a seleção de refratários de revestimento em cadinhos no transporte do alumínio líquido.

Desse modo, optou-se também neste trabalho pela realização de ensaios de permeabilidade a quente em um material utilizado em cadinhos, dada a motivação decorrente do potencial tecnológico envolvido no transporte de metal fundido.

\section{Permeabilidade em alta temperatura}

A permeabilidade de um material é caracterizada quando um fluido é forçado a atravessar um meio poroso. A complexa interação existente entre o fluido e o canal poroso ocasiona uma mudança na energia do sistema, normalmente gerando uma queda da pressão exercida pelo fluido [8].

A equação de Forchheimer, utilizada para fluidos compressíveis (gases e vapores), é a mais adequada para uso em um meio rígido e homogêneo:

$$
\frac{P_{i}^{2}-P_{o}^{2}}{2 \cdot P_{0} \cdot L}=\frac{\mu}{k_{1}} v_{s}+\frac{\rho}{k_{2}} v_{s}^{2}
$$

onde, $\mathrm{P}_{\mathrm{i}}=$ pressão absoluta do fluido na entrada da amostra, $\mathrm{P}_{\mathrm{o}}=$ pressão absoluta na saída, $\mathrm{v}_{\mathrm{s}}=$ velocidade superficial do fluido (saída volumétrica de ar/área total de fluxo), $\mathrm{L}=$ espessura da amostra, $\mu=$ viscosidade do fluido, $\rho=$ densidade do fluido calculada para $\mathrm{P}_{\mathrm{o}}, \mathrm{k}_{1}=$ constante de permeabilidade Darciana e $\mathrm{k}_{2}=$ constante de permeabilidade não Darciana [9].

$\mathrm{O}$ parâmetro $\mathrm{k}_{1}$ está associado aos efeitos viscosos durante o escoamento em baixas velocidades, ou seja, ao atrito entre as moléculas do fluido e deste com as paredes do meio poroso. Já $\mathrm{k}_{2}$ se relaciona à perda de energia em velocidades de fluxo elevadas, sendo intensificado em decorrência de fatores como a turbulência do escoamento e a tortuosidade do meio poroso [10].

De acordo com Innocentini et al. [11], a equação de Forchheimer permite o cálculo de constantes de permeabilidade mais realistas ou confiáveis para a caracterização de cerâmicas refratárias, pois considera os efeitos turbulentos de fluxo em altas velocidades e também os efeitos da compressibilidade do fluido.

Em cerâmicas refratárias pré-formadas, a morfologia e a quantidade de poros refletem diretamente na permeabilidade. Os poros existentes nestes materiais podem ser classificados em três formas distintas: (1) poros abertos e não conectados, que permitem a penetração limitada do fluido, sem 
permeação total da amostra; (2) poros fechados, normalmente associados aos agregados que constituem o refratário ou da matriz originada durante o processo de queima; e (3) poros abertos e conectados, responsáveis pela permeabilidade do refratário.

Para testes conduzidos em alta temperatura, uma vez que ocorrem alterações nas propriedades do fluido, é necessário efetuar correções apropriadas nos valores de densidade e viscosidade do ar [9]:

$$
\begin{aligned}
& \rho_{\mathrm{ar}}(T)=\rho_{\mathrm{r}} \frac{T_{\mathrm{r}}}{T} \frac{P}{P_{r}} \\
& \mu_{\mathrm{ar}}(T)=1,73 \times 10^{-5}\left(\frac{T}{273}\right)^{1,5}\left(\frac{398}{T+125}\right)
\end{aligned}
$$

onde $\rho_{\mathrm{r}}=$ densidade do gás na temperatura de referência $\left(\mathrm{T}_{\mathrm{r}}\right)$ e $\mathrm{P}_{\mathrm{r}}=$ pressão de referência. Neste trabalho, utilizou-se $\rho_{\mathrm{r}}=$ $1,29 \mathrm{~kg} / \mathrm{m}^{3}$ a $\mathrm{T}_{\mathrm{r}}=273 \mathrm{~K} \mathrm{e} \mathrm{P}_{\mathrm{r}}=1,013 \times 10^{5} \mathrm{~Pa}$. A equação C é conhecida como equação de Sutherland.

Adicionalmente, como a velocidade do ar $\left(\mathrm{v}_{\mathrm{so}}\right)$ é somente calculada na temperatura $\left(\mathrm{T}_{\mathrm{amb}}\right)$ e pressão ambiente $\left(\mathrm{P}_{\mathrm{amb}}\right)$, a velocidade real na saída da amostra durante o ensaio é dada por [9]:

$$
\mathrm{v}_{\mathrm{s}}(\mathrm{T})=\mathrm{v}_{\mathrm{so}} \frac{\mathrm{T}}{T_{\mathrm{amb}}} \frac{P_{\mathrm{amb}}}{\mathrm{P}}
$$

Assim, através destas correções necessárias para ensaios em temperaturas distintas da ambiente, torna-se possível averiguar a permeabilidade do material em condições mais próximas da situação real, resultando em uma maior confiabilidade na seleção de revestimentos refratários.

\section{MATERIAIS E MÉTODOS}

Cinco refratários comerciais (A, B, C, D e E) para revestimento de cubas foram escolhidos para a avaliação da permeabilidade em alta temperatura. Adicionalmente, um refratário comercial para revestimento de cadinhos (F, quimicamente ligado) foi pesquisado.

A partir de tijolos previamente conformados, foram extraídos corpos de prova cilíndricos com $70 \mathrm{~mm}$ de diâmetro, os quais foram retificados até que atingissem uma espessura de $23 \mathrm{~mm}$. A Tabela I apresenta a composição química desses materiais.

As medidas de permeabilidade efetuadas neste trabalho foram realizadas em um permeâmetro de alta temperatura desenvolvido por Innocentini e outros [9]. Algumas adaptações para a vedação da amostra foram necessárias para que o equipamento pudesse ser utilizado para os refratários deste estudo. Devido a menor resistência mecânica dos materiais testados, foi aumentada a área de contato do anel elástico com a amostra, distribuindo melhor
Tabela I - Composição química dos refratários sílico-aluminosos para a indústria do alumínio. A composição química do refratário $\mathrm{F}$ foi baseada somente em sua ficha técnica.

[Table I - Chemical composition of SiAl refractories for the aluminum industry. The chemical composition of refractory $F$ was only based on its datasheet.]

\begin{tabular}{ccccccc}
\hline $\begin{array}{c}\text { Componente } \\
\text { (\%peso) }\end{array}$ & $\mathrm{A}$ & $\mathrm{B}$ & $\mathrm{C}$ & $\mathrm{D}$ & $\mathrm{E}$ & $\mathrm{F}$ \\
\hline $\mathrm{Al}_{2} \mathrm{O}_{3}$ & 24,3 & 22,4 & 24,7 & 25,0 & 52,6 & $>46$ \\
$\mathrm{SiO}_{2}$ & 69,3 & 68,4 & 70,5 & 68,9 & 40,6 & $>56$ \\
$\mathrm{Fe}_{2} \mathrm{O}_{3}$ & 1,13 & 1,57 & 0,61 & 1,16 & 2,10 & $>2,5$ \\
$\mathrm{TiO}_{2}$ & 0,95 & 0,54 & 0,81 & 1,36 & 2,32 & - \\
$\mathrm{CaO}$ & 0,95 & 0,62 & traços & traços & traços & - \\
$\mathrm{MgO}$ & 0,31 & 0,35 & 0,03 & 0,11 & 0,21 & - \\
$\mathrm{Na}_{2} \mathrm{O}$ & 0,21 & 0,74 & 0,29 & 0,21 & 0,25 & \\
$\mathrm{~K}_{2} \mathrm{O}$ & 2,39 & 3,40 & 2,06 & 2,65 & 1,33 & \\
$\mathrm{P}_{2} \mathrm{O}_{5}$ & traços & 1,45 & 0,07 & 0,13 & 0,23 & \\
$\mathrm{Outros}^{2}$ & 0,46 & - & 0,93 & 0,48 & 0,36 & - \\
Perda ao & 1,86 & 0,45 & 0,25 & 0,77 & traços & - \\
fogo & & & & & & \\
\hline
\end{tabular}

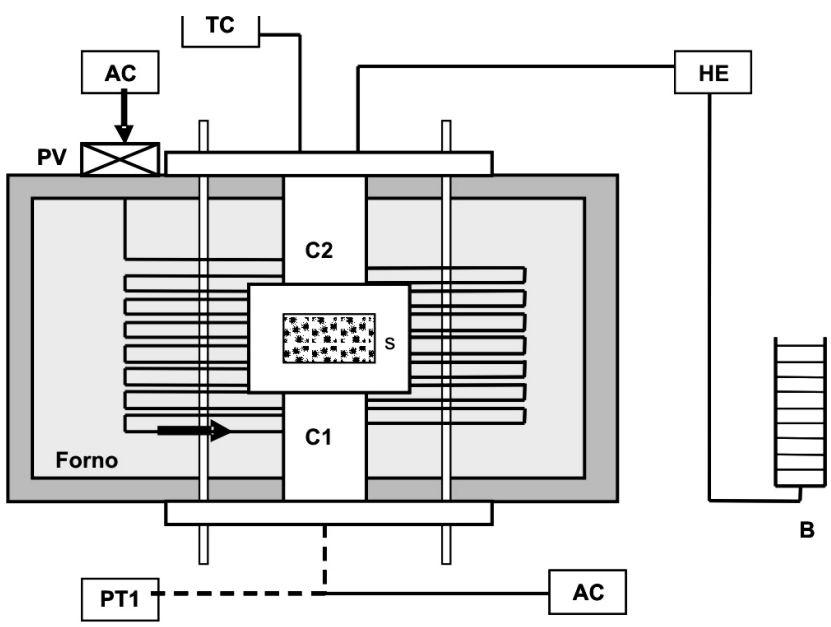

AC: Compressor de ar $2 \mathrm{HP}$

B: Bolhômetro - para medição de vazão $(Q=0$ a $10 \mathrm{~L} / \mathrm{min})$

C1 - C2: Câmaras, V = $140 \mathrm{~cm}$

PV: Válvula de pressão e filtro de óleo

PT1: Transdutor para a leitura de pressão de entrada ( $\mathrm{PI}<10$ bar)

S: Amostra $(D=7,5 \mathrm{~cm}, \mathrm{~L}=2-3 \mathrm{~cm})$

TC: Termopares

Figura 1: Desenho esquemático do permeâmetro de alta temperatura adaptado para materiais cerâmicos refratários sílico-aluminosos [9]. [Figure 1: Sketch of the high temperature permeameter adapted for evaluating alumino-silicate refractories [9].]

a tensão mecânica para se evitar trincamentos. Um desenho esquemático do equipamento é apresentado na Fig. 1.

A técnica adotada neste estudo foi a permeametria em estado estacionário $[10,11]$ onde a vazão volumétrica $Q$ é medida em uma determinada temperatura, mantendo $\mathrm{P}_{\mathrm{i}}$ e $\mathrm{P}_{\mathrm{o}}$ constantes. As temperaturas de estabilização empregadas foram $250 \pm 5^{\circ} \mathrm{C}, 490 \pm 5^{\circ} \mathrm{C}, 590 \pm 5^{\circ} \mathrm{C}$ e $695 \pm 5^{\circ} \mathrm{C}$ sob a taxa de aquecimento de $3{ }^{\circ} \mathrm{C} / \mathrm{min}$. 
A faixa de pressão foi escolhida de modo a não ultrapassar o limite máximo de detecção de vazão do dispositivo. Desta forma, foram selecionados 20 pontos de pressão entre 0,30 e 2,20 bar, garantindo total varredura da faixa desejada para os refratários em estudo.

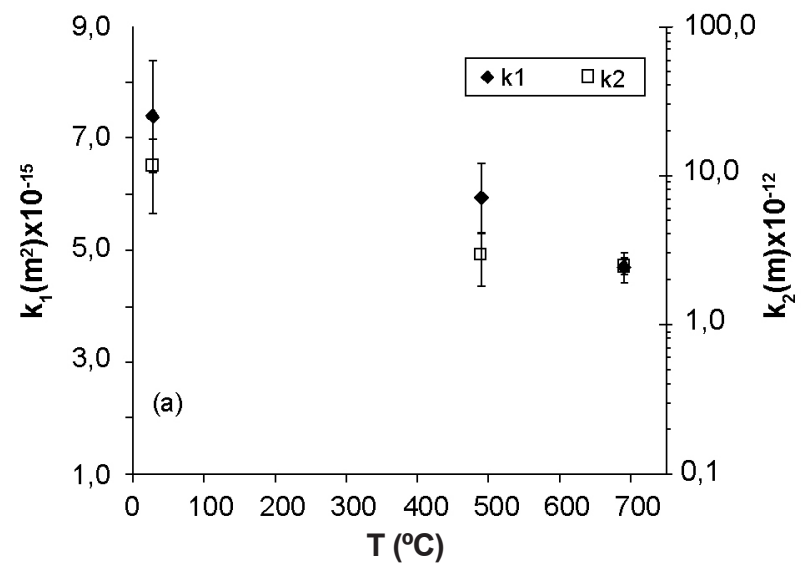

\section{RESULTADOS E DISCUSSÃO}

Visando-se verificar a confiabilidade dos resultados obtidos no permeâmetro, os refratários A e D foram ensaiados por três vezes para a análise da reprodutibilidade

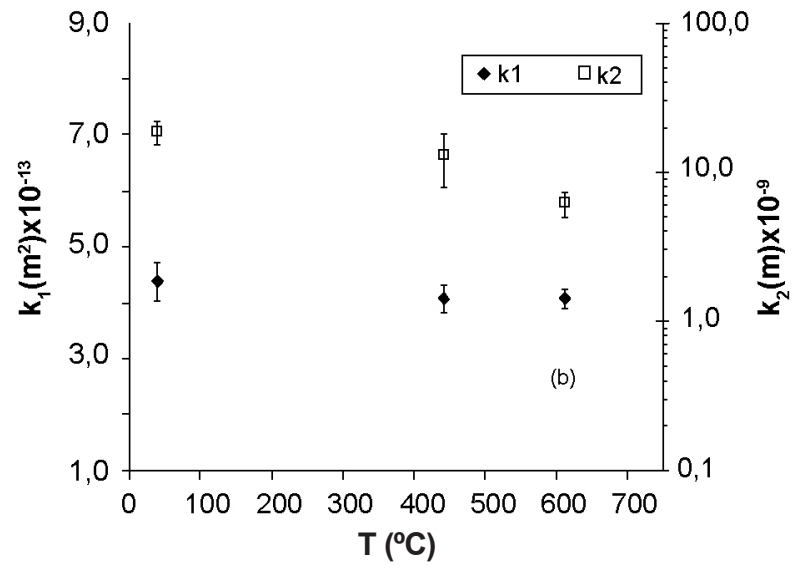

Figura 2: Erro estimado para a medida da permeabilidade dos refratários A (a) e D (b).

[Figure 2: Expected measurement error for permeability of refractories $A$ (a) and $D(b)$.]

Refratário A
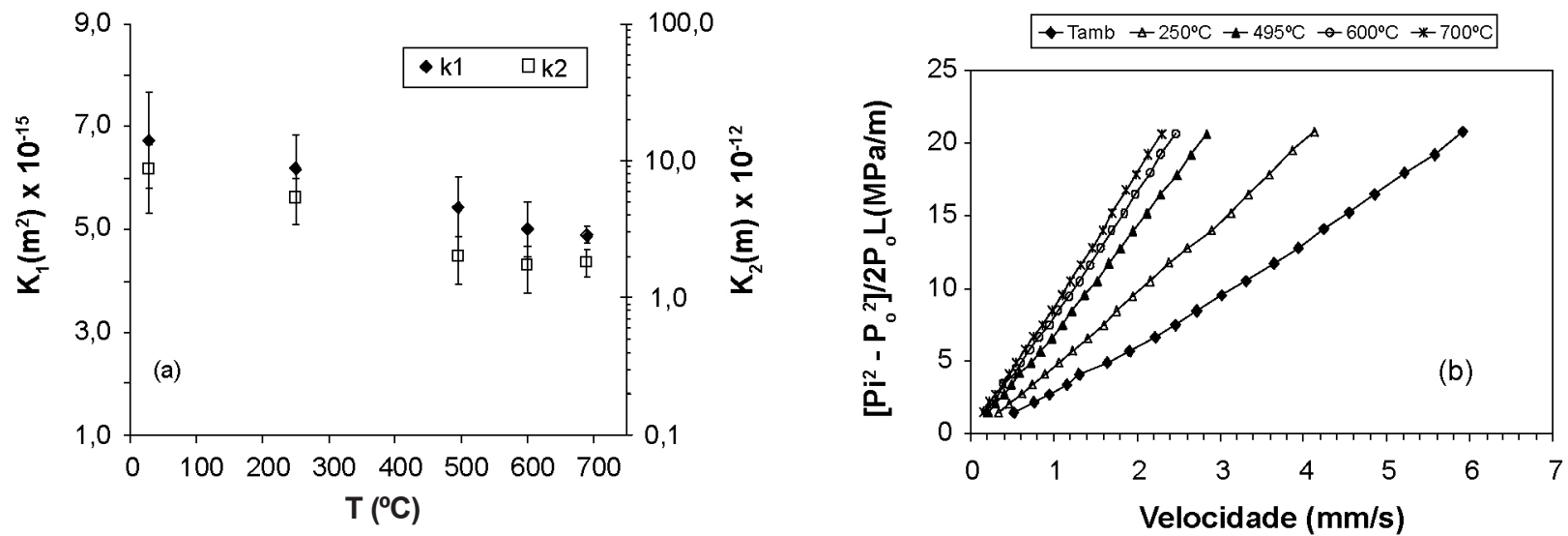

Refratário B
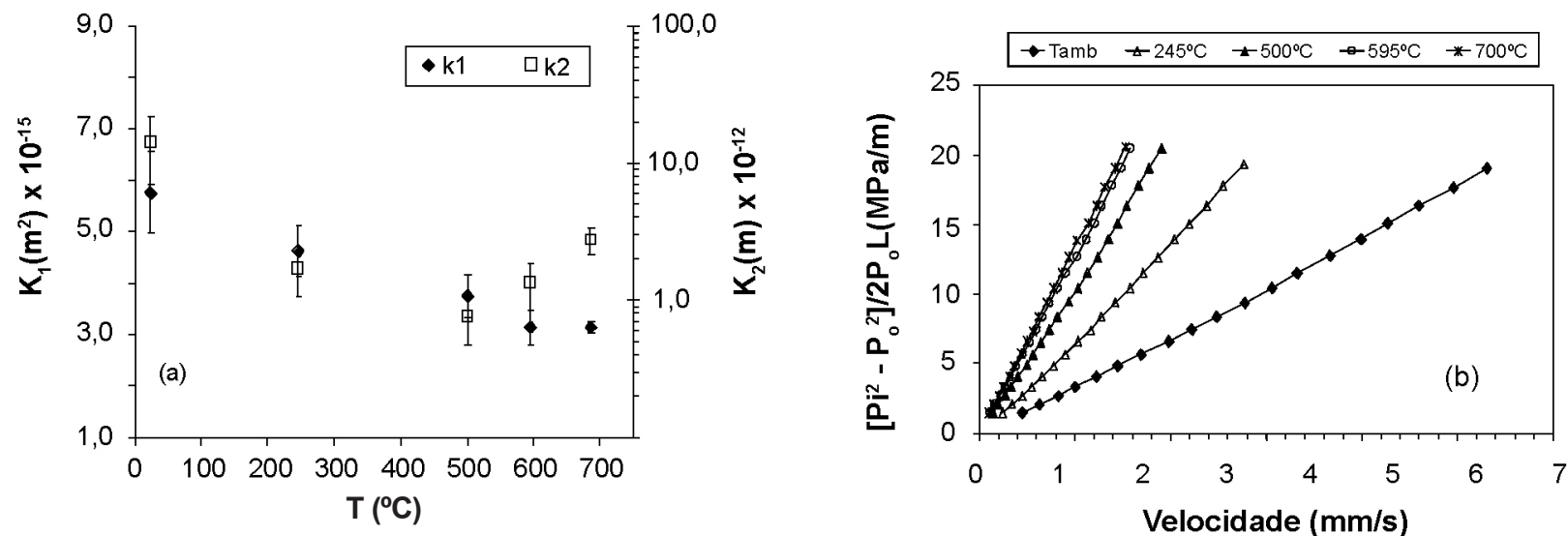

Figura 3: Gráfico de permeabilidade em função da temperatura para os refratários A e B (a) e seus respectivos gráficos de queda de pressão em função da velocidade (b).

[Figure 3: Permeability versus temperature for refractories $A-B(a)$ and their correspondent pressure drop versus air velocity results (b).] 
Refratário C
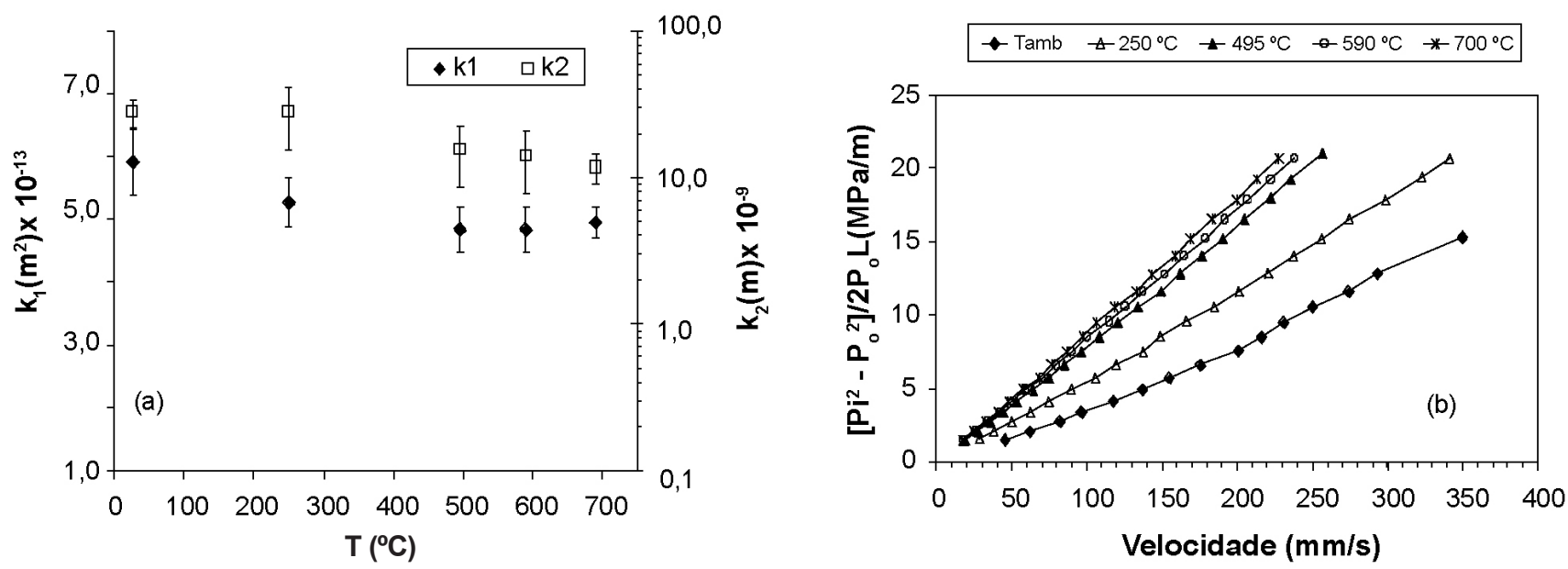

Refratário D
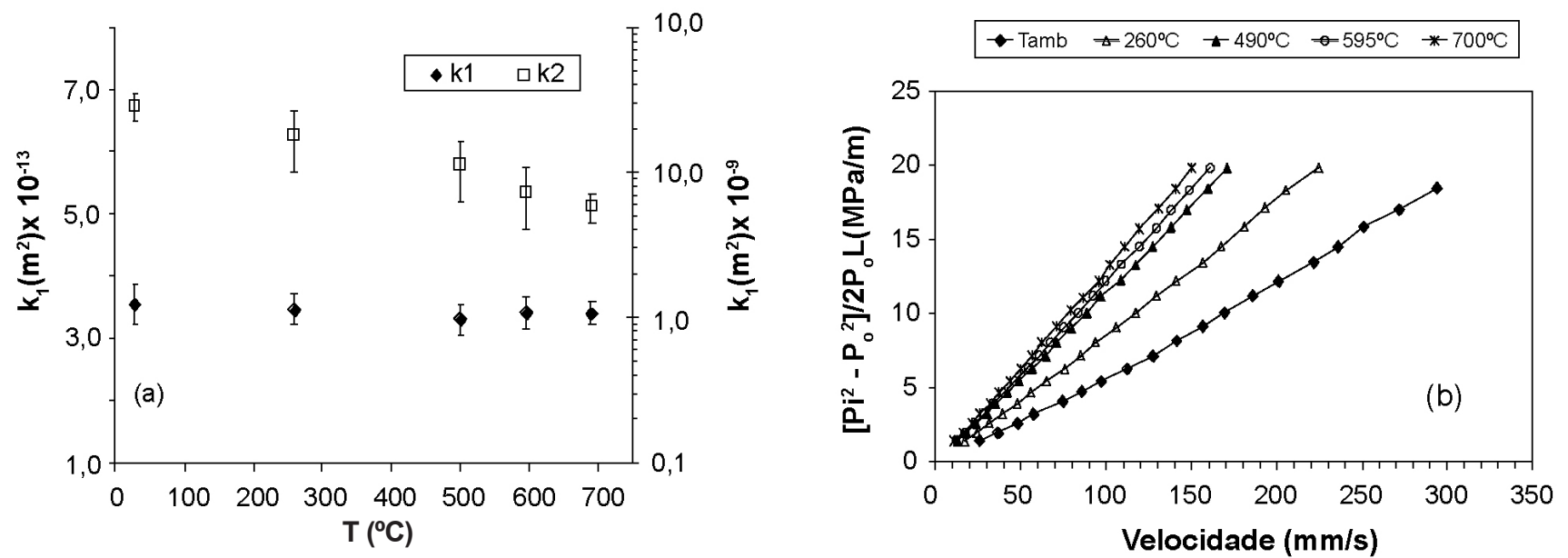

Refratário E
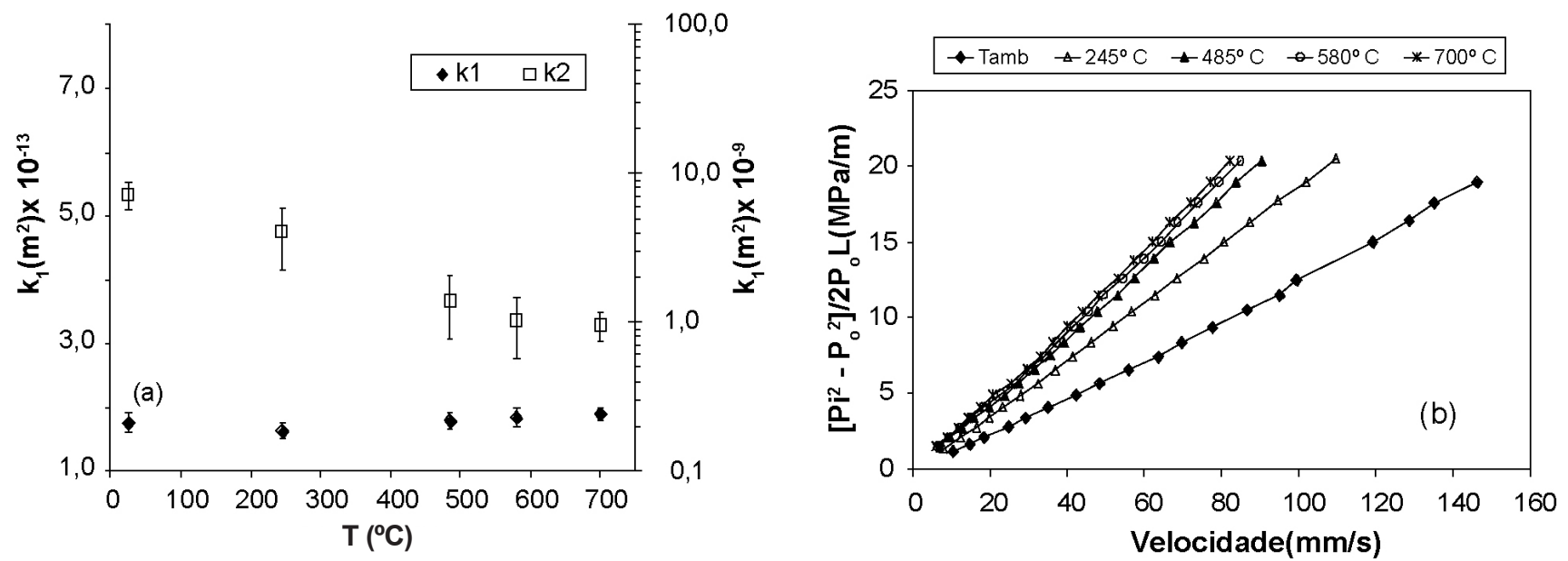

Figura 4: Gráfico de permeabilidade em função da temperatura para os refratários C - E (a) e seus respectivos gráficos de queda de pressão em função da velocidade (b).

[Figure 4: Permeability versus temperature for refractories $C-E(a)$ and their correspondent pressure drop versus air velocity results (b).] 
Refratário F1
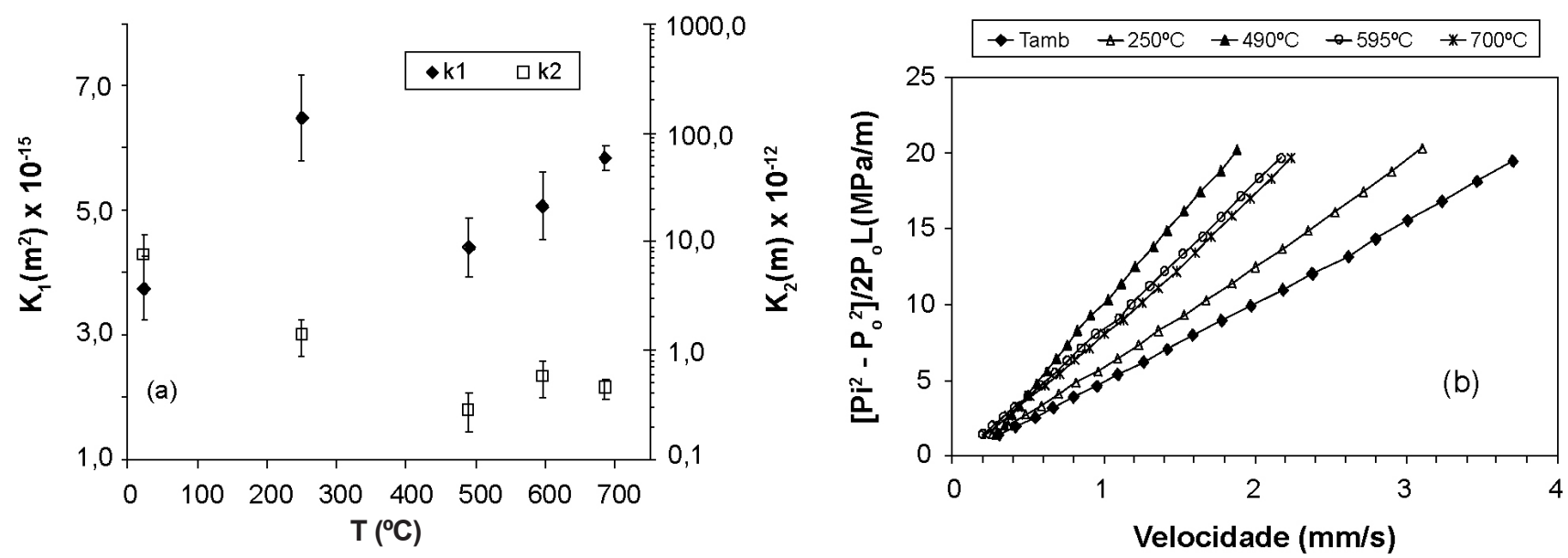

\section{Refratário FR}
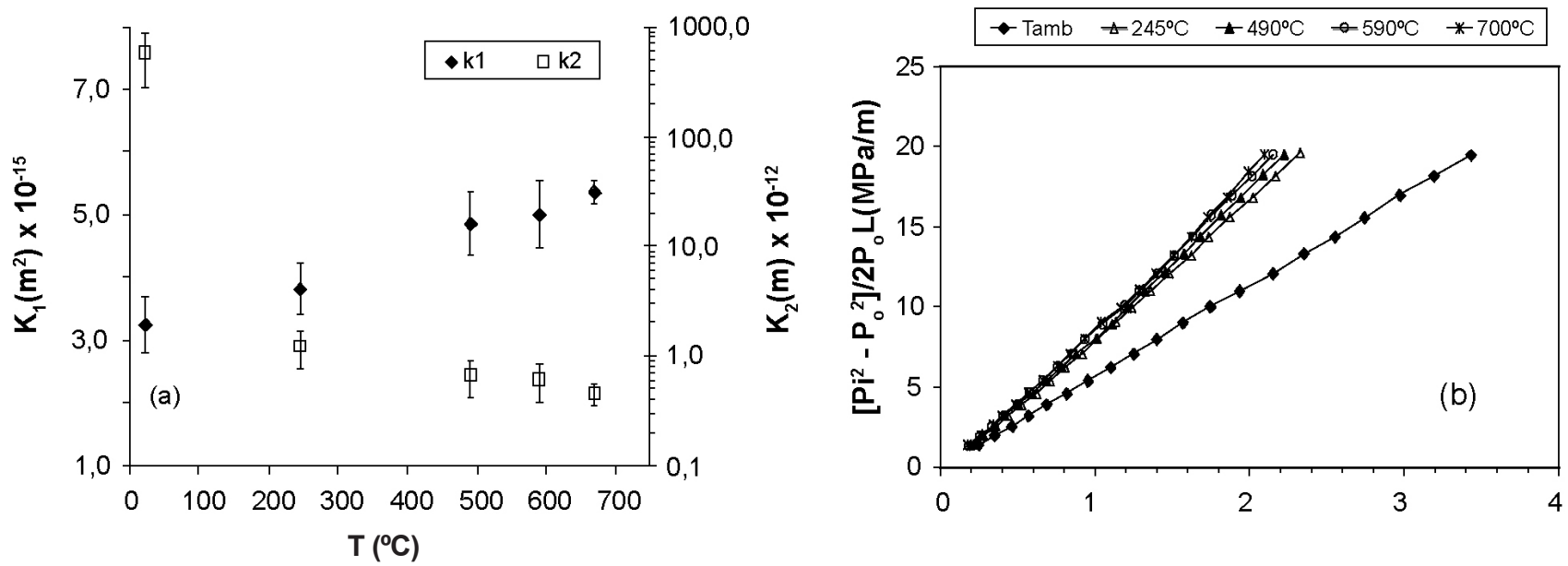

Refratário F2
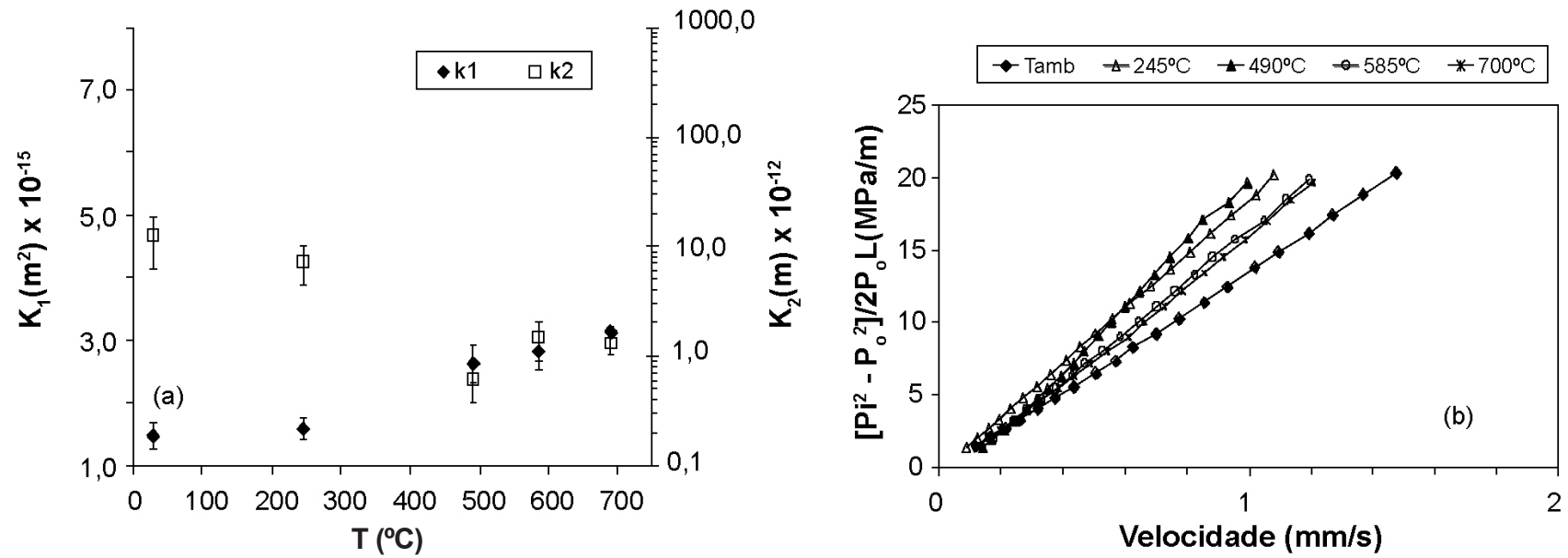

Figura 5: Gráfico de permeabilidade em função da temperatura para o refratário $\mathrm{F}$ (a) e seu respectivo gráfico de queda de pressão em função da velocidade (b). F1 e F2 são refratários ensaiados assim como recebidos. FR expressa os resultados e um novo ensaio no refratário F1. [Figure 5: Permeability versus temperature for refractory $F(a)$ and its correspondent pressure drop versus air velocity results (b). F1 and $F 2$ are as received tested samples, $F R$ is the permeability reevaluation of refractory $F 1$. 
Tabela II - Comparação geral dos refratários de revestimento para cubas eletrolíticas.

[Table II - Electrolytic cell refractories lining's properties.]

\begin{tabular}{cccccc}
\hline & $\begin{array}{c}\mathrm{Razão}_{2} \\
\mathrm{Al}_{2} \mathrm{O}_{3}\end{array}$ & $\begin{array}{c}\mathrm{k}_{1}\left(\mathrm{~m}^{2}\right) \\
\mathrm{Tamb}\end{array}$ & $\begin{array}{c}\mathrm{k}_{1}\left(\mathrm{~m}^{2}\right) \\
690{ }^{\circ} \mathrm{C}\end{array}$ & $\begin{array}{c}\mathrm{k}_{2}(\mathrm{~m}) \\
\mathrm{Tamb}\end{array}$ & $\begin{array}{c}\mathrm{k}_{2}(\mathrm{~m}) \\
690^{\circ} \mathrm{C}\end{array}$ \\
\cline { 2 - 5 } & $\mathrm{SiO}_{2}$ & & & & \\
\hline $\mathrm{A}$ & 0,35 & $6,7 \times 10^{-15}$ & $4,8 \times 10^{-15}$ & $8,6 \times 10^{-12}$ & $1,8 \times 10^{-12}$ \\
$\mathrm{~B}$ & 0,33 & $6,7 \times 10^{-15}$ & $3,4 \times 10^{-15}$ & $9,4 \times 10^{-12}$ & $2,8 \times 10^{-12}$ \\
$\mathrm{C}$ & 0,35 & $5,9 \times 10^{-13}$ & $4,9 \times 10^{-13}$ & $2,8 \times 10^{-8}$ & $1,1 \times 10^{-8}$ \\
$\mathrm{D}$ & 0,35 & $3,5 \times 10^{-13}$ & $3,4 \times 10^{-13}$ & $2,9 \times 10^{-8}$ & $5,8 \times 10^{-9}$ \\
$\mathrm{E}$ & 0,77 & $1,7 \times 10^{-13}$ & $1,9 \times 10^{-13}$ & $7,2 \times 10^{-9}$ & $9,5 \times 10^{-10}$ \\
\hline
\end{tabular}

e variabilidade das medidas, encontrando-se, assim, um erro associado ao equipamento. De acordo com a Fig. 2, observa-se que estes materiais distintos não possuem a mesma amplitude de erro. Deste modo, foi estimado um erro padrão, considerando-se a média e o desvio, de acordo com a faixa de vazão adequada de cada tipo de material. Tais resultados indicaram que os valores de permeabilidade variaram no máximo 3 unidades dentro de uma mesma ordem de grandeza, considerando os efeitos de acoplamento da amostra para diferentes ensaios e os desvios na medida para uma mesma temperatura.

As Figs. 3 a 5 apresentam os resultados obtidos de permeametria a quente dos refratários selecionados por meio de gráficos das constantes de permeabilidade $\mathrm{k}_{1}$ e $\mathrm{k}_{2}$ versus temperatura, conjuntamente com os respectivos gráficos de queda de pressão $\left(\mathrm{P}_{\mathrm{i}}^{2}-\mathrm{P}_{\mathrm{o}}^{2} / 2 \mathrm{P}_{\mathrm{o}} \mathrm{L}\right)$ em função da velocidade do fluido $\left(\mathrm{v}_{\mathrm{s}}\right)$.

Como pode ser observado nos gráficos $3 \mathrm{a}$ e $4 \mathrm{a}$, existe uma tendência geral de redução da permeabilidade, detectada pela diminuição do valor de $\mathrm{k}_{2}$ quando se comparam os valores obtidos a temperatura ambiente e a $700{ }^{\circ} \mathrm{C}$, enquanto que o valor de $\mathrm{k}_{1}$ é praticamente inalterado, considerando-se o erro associado às diferentes medidas. De acordo com as afirmações de Innocentini et al. [9], atribui-se que a queda de $\mathrm{k}_{2}$ é ocasionada pela diminuição do diâmetro médio dos poros com o aumento da temperatura, tornando o caminho do fluxo mais tortuoso. Estes resultados apresentados indicam que medidas de permeabilidade na temperatura ambiente parecem ser suficientes para o processo de seleção de refratários, pois mostram, de forma comparativa, quais são os materiais adequados, ou seja, menos permeáveis.

Estudos apresentados por Bonadia e cols.[4], mostraram a existência de uma correlação entre permeabilidade a temperatura ambiente e a área de degradação do banho criolítico no ensaio de "cup test". Entretanto, conforme pode ser percebido pela Tabela II, materiais com razão $\mathrm{Al}_{2} \mathrm{O}_{3}$ / $\mathrm{SiO}_{2}$ adequada $(\sim 0,35)$ não necessariamente apresentam os melhores resultados de permeabilidade. Assim, não é possível estabelecer, neste estudo, uma comparação direta entre a permeabilidade e a composição química dos refratários: enquanto os materiais $\mathrm{C}$ e $\mathrm{D}$ apresentam maior permeabilidade do que o refratário com maior teor de alumina
(E), os materiais A e B se mostram menos permeáveis, mesmo possuindo composições químicas semelhantes às de $\mathrm{C}$ e D.

A afirmação de que o refratário $\mathrm{E}$ possui menor permeabilidade em relação aos materiais $\mathrm{C}$ e $\mathrm{D}$ é efetuada principalmente com base no valor de $\mathrm{k}_{2}$ a temperatura ambiente, que apresenta diferenças nos resultados de mais de meia ordem de grandeza. Os gráficos de queda de pressão em função da velocidade de permeação são fundamentais para a compreensão do significado dessa diferença. Comparandose os valores para uma mesma queda de pressão, o fluxo de ar dos refratários C e D (Fig. 4 índices "b") atingem de duas a quatro vezes a velocidade do fluido que permeia o refratário E (Fig. 4).

Quando comparado aos refratários para cubas eletrolíticas, o material F (utilizado em cadinhos de transporte de alumínio líquido) apresentou resultados bastante particulares. Para o refratário F1 (índice "a") da Fig. 5, é observada uma redução da permeabilidade de aproximadamente uma ordem e meia de grandeza entre a temperatura ambiente e $500{ }^{\circ} \mathrm{C}$ quando se considera $\mathrm{k}_{2}$. Neste caso, é possível que

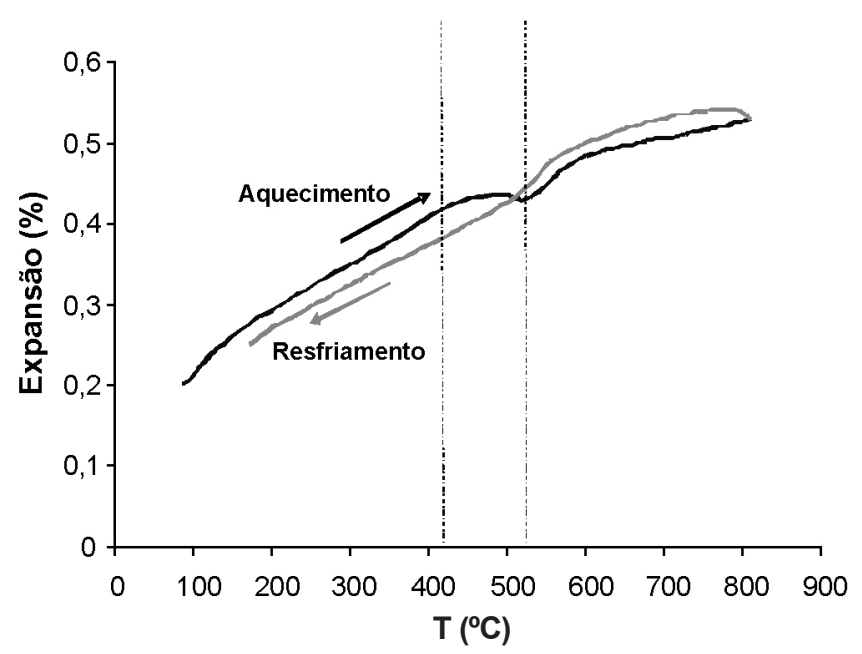

Figura 6: Ensaio de dilatometria do refratário F.

[Figure 6: Dilatometry test of refractory F.]

Tabela III - Resultados do ensaio de porosidade em cada corpo de prova refratário submetido ao ensaio de permeabilidade.

[Table III - Porosity test of each refractory sample subjected to the permeability test.]

\begin{tabular}{ccc}
\hline Refratário & $\begin{array}{c}\text { Porosidade } \\
\text { aparente } \\
\text { inicial (\%) }\end{array}$ & $\begin{array}{c}\text { Porosidade aparente } \\
\text { final (\%) após o } \\
\text { ensaio de permeabilidade }\end{array}$ \\
\hline A & $5,20 \pm 0,04$ & $5,5 \pm 0,2$ \\
B & 10,8 & 10,9 \\
C & 15,0 & 15,1 \\
D & $14,4 \pm 0,4$ & $15,0 \pm 0,1$ \\
E & 18,3 & 18,7 \\
F 1/FR & $15,0 \pm 0,1$ & $15,4-15,7$ \\
F 2 & 14,8 & 15,7 \\
\hline
\end{tabular}


tenham ocorrido transformações microestruturais durante o aquecimento originando uma estrutura de poros conectados distinta daquela à temperatura ambiente. Para comprovar este comportamento, dois ensaios complementares foram realizados. Os ensaios foram repetidos nas mesmas condições experimentais para o corpo de prova já ensaiado em função da temperatura FR e para um novo corpo de prova (F2), extraído do mesmo tijolo.

Nota-se, no ensaio de FR, uma tendência distinta do perfil de permeabilidade em relação à temperatura, com um contínuo decréscimo de $\mathrm{k}_{2}$ à medida que a temperatura é elevada. Entretanto, F2 mostra novamente a existência de um ponto mínimo na temperatura de $500{ }^{\circ} \mathrm{C}$, indicando uma modificação significante na permeabilidade do refratário $\mathrm{F}$ durante um primeiro ensaio, ou seja, durante o primeiro aquecimento. Analisando-se a curva de queda de pressão à $490{ }^{\circ} \mathrm{C}$ (Fig. 5 índices "b"), alguns pontos de menor velocidade de fluxo são notados em relação às outras temperaturas. Porém, na repetição do ensaio do mesmo corpo de prova (Fig. 5 refratário FR), esse comportamento não é observado, implicando na possibilidade da existência de algum fenômeno de caráter irreversível estar ocasionando esta redução na permeabilidade. A causa deste comportamento pode estar relacionada ao fato deste material F ser quimicamente ligado e ser pré-tratado em temperaturas na faixa de $200{ }^{\circ} \mathrm{C}$ a $500{ }^{\circ} \mathrm{C}$.

$\mathrm{O}$ ensaio de dilatometria do refratário $\mathrm{F}$ assim como recebido (Fig. 6), evidencia uma expansão térmica significativamente menor entre $410{ }^{\circ} \mathrm{C}$ a $525{ }^{\circ} \mathrm{C}$ durante o aquecimento, havendo inclusive uma contração subseqüente. É provável que uma transformação mineralógica possa estar contribuindo para mudanças microestruturais, alterando a conectividade entre os poros. No resfriamento da amostra, pode-se perceber uma atenuação dessa transformação na mesma faixa de temperatura, o que sugere irreversibilidade do fenômeno.

Adicionalmente, com a finalidade de se complementar os resultados obtidos nos ensaios de permeabilidade, foram determinadas as porosidades aparentes pelo método de imersão em todos os corpos de prova (baseado na norma ASTM C20). Estas medidas procuraram avaliar se os ensaios de permeabilidade em alta temperatura estariam causando alterações microestruturais nos materiais. A partir dos dados da Tabela III, observa-se que não houve alterações significativas na porosidade dos refratários para cubas após o ensaio de permeabilidade. Deste modo, atribui-se que os desvios visualizados na Fig. 2 resultam da influência da temperatura para os materiais A-E e não devido a mudanças do próprio material.

$\mathrm{O}$ refratário $\mathrm{F}$ apresentou uma maior variação na porosidade em relação aos revestimentos de cubas e uma elevada perda de massa (da ordem de 1,5\%) após o ensaio a $680{ }^{\circ} \mathrm{C}$. Assim, além de transformações microestruturais, o material apresenta uma variação de massa, provavelmente devido a alterações no sistema ligante. Sabe-se que os refratários quimicamente ligados pré-queimados a baixas temperaturas são suscetíveis a absorção de água do meio, sendo que este pode ter sido o motivo de tal resultado.

Comparando-se os valores de porosidadee permeabilidade nas Tabelas II e III, percebe-se que os refratários para cubas menos porosos (A e B) são também menos permeáveis. Apesar da disparidade de valores da porosidade entre os materiais A e B, acredita-se que ambos possuam uma conectividade de poros abertos similares, promovendo permeabilidades semelhantes. Esta mesma consideração pode ser feita para o refratário E que, apesar de ser menos permeável que os materiais $\mathrm{C}$ e $\mathrm{D}$, possui maior porosidade, porém, menos conectada.

Como a porosidade não expressa a morfologia dos poros, que é de grande relevância para prever a penetração, a medida de permeabilidade é um aspecto essencial de caracterização destes materiais usados em cubas eletrolíticas.

\section{CONCLUSÕES}

Foi verificada a variação na permeabilidade a quente de refratários para revestimento de cubas eletrolíticas para produção de alumínio primário. Os resultados obtidos mostraram que para os materiais pré-queimados em temperaturas acima das usadas nos ensaios, a permeabilidade não-Darciana $\mathrm{k}_{2}$ decresce durante o aquecimento em relação à temperatura ambiente. Sendo assim, um ensaio a temperatura ambiente já pode ser considerado como uma referência tecnológica suficiente para a seleção desses materiais préqueimados, no que diz respeito à permeabilidade.

O refratário para revestimento de cadinhos utilizados em transporte de alumínio líquido mostrou a importância de se considerar as possíveis reações envolvidas quando o material não foi pré-queimado a alta temperatura. Notouse também que, dependendo das alterações em que o sistema ligante do refratário fica sujeito, a permeabilidade pode se modificar com a temperatura. Além do refratário utilizado neste estudo (F), um comportamento similar seria encontrado para concretos refratários contendo cimento, cuja permeabilidade aumenta em função da temperatura na faixa de $110{ }^{\circ} \mathrm{C}$ a $350{ }^{\circ} \mathrm{C}$, quando as fases de aluminato de cálcio hidratadas se decompõem.

Nestes casos, a permeametria a quente se apresenta como uma importante técnica de caracterização, podendo fornecer resultados mais próximos da situação de operação, além de um melhor entendimento microestrutural durante a etapa de aquecimento.

\section{AGRADECIMENTOS}

A Alcoa Alumínio S.A. e ao CNPq pelo apoio dado ao estudo.

\section{REFERÊNCIAS}

[1] O. J. Siljan, T. Grande, C. Shoning, Aluminum 77, 5 (2001), 385.

[2] O. J. Siljan, T. Grande, C. Shoning, Aluminum 77, 10 (2001) 809. 
[3] W. Walz, Interceram 50, 3 (2001) 170.

[4] P. Bonadia, F. A. O. Valenzuela, L. R. Bittencout, V. C. Pandolfelli, Am. Ceram. Soc. Bull. 2, 84 (2005) 26.

[5] W. S. Resende, C. Zirpoli, G. L. Silva, S. A. Sucupira, Refractories Applications and News 7, 1 (2002) 20.

[6] R. D. Peterson, G. G. Blag, 4 ${ }^{\text {th }}$ Int. Symp. Recycling Metals and Eng. Mater., Pittsburgh (2000) 857.

[7] M. A. L. Braulio, P. Bonadia, J. B. Gallo, V. C. Pandolfelli, Cerâmica 52, 323 (2005) 217.

[8] M. D. M. Innocentini, V. C. Pandolfelli Cerâmica 45,
292-293 (1999) 61.

[9] M. D. M. Innocentini, M. G. Silva, B. A. Menegazzo, V. C. Pandolfelli, J. Am. Ceram. Soc. 84, 3 (2001) 645.

[10] M. D. M Innocentini, A. R. F. Pardo, V. R. Salvini, V. C. Pandollfeli, Cerâmica 48, 305 (2002) 5.

[11] M. D. M. Innocentini, A. R. F. Pardo, V. C. Pandollfeli, J. Am. Ceram. Soc. 83, 6 (2000) 1536.

[12] M. D. M. Innocentini, A. R. F. Pardo, V. C. Pandollfeli, Proc. Unified Int. Tech. Conf . Refractories, Bonn, Germany (1999) 269.

(Rec. 30/07/2005, Ac. 03/02/2006) 